\title{
An environmental performance resource impact indicator for life cycle management in the manufacturing industry
}

\author{
A. C. Brent ${ }^{a}$ and J. K. Visser ${ }^{b}$ \\ ${ }^{a}$ Life Cycle Engineering, Room 4-12, Engineering 2, Pretoria 0002, South Africa \\ ${ }^{\mathrm{b}}$ Department of Engineering and Technology Management, University of Pretoria, \\ Pretoria 0002, South Africa
}

\begin{abstract}
Life cycle management (LCM) implies that the environmental impacts associated with suppliers must be incorporated in the decision-making framework of manufacturing facilities. In the developing country context, little environmental information is available and an environmental performance resource impact indicator (EPRII) is proposed to assess suppliers based on three simple operational parameters: water use, energy use, and waste produced. By translating EPRII results per economic value, it is shown that the operational expenditure of an automotive original equipment manufacturer on suppliers is not directly related to the environmental burdens associated with supplied components. From a product LCM perspective, the EPRII approach can reflect the environmental burdens per assembled product or automobile.
\end{abstract}

\section{Article Outline}

1. Introduction

1.1. Product life cycle management and supply chain management

2. Environmental performance resource impact indicator (EPRII) procedure

2.1. Resource impact indicator (RII) calculation procedure

2.2. Environmental performance resource impact indicator procedure

3. Performance evaluation of three automotive OEM suppliers in South Africa

4. Conclusions

References 


\section{Introduction}

Government laws and policies are increasingly introducing the principles of sustainable development on a global scale, which in turn affect international trade agreements [1]. Businesses, especially multinationals, are consequently pressurised to incorporate economic, environmental and social performances in their policies, culture and decisionmaking processes [2]. These performances objectives manifest in three operational focal points that are fundamental to the manufacturing industry [3]:

- Projects, which drive change in internal operational practices. The concept of sustainable development must be integrated in the planning and management over the life cycle of projects [3 and 4].

- Assets, which are required in the manufacturing process. The life cycle of assets must be optimised in terms of sustainable development performance objectives of the manufacturing facility [5, 6, 7 and 8$]$.

- Products, which determine the economic value of manufacturing operations. The influence of products on economies, environments and society as a whole must be considered, i.e. the concept of product stewardship [9].

A comprehensive life cycle management (LCM) approach is subsequently required, which assures that the operational processes are consistent and that there is effective sharing and coordination of resources, information and technologies [10]. Such a holistic LCM approach in the manufacturing sector would require an effective integration of the three life cycles within the organisation (Fig. 1) [11]. Thereby, from Fig. 1, product LCM forms an integral part of the operations phase of asset LCM, which in turn is the outcome of projects that are typically undertaken in the manufacturing industry [3]. 


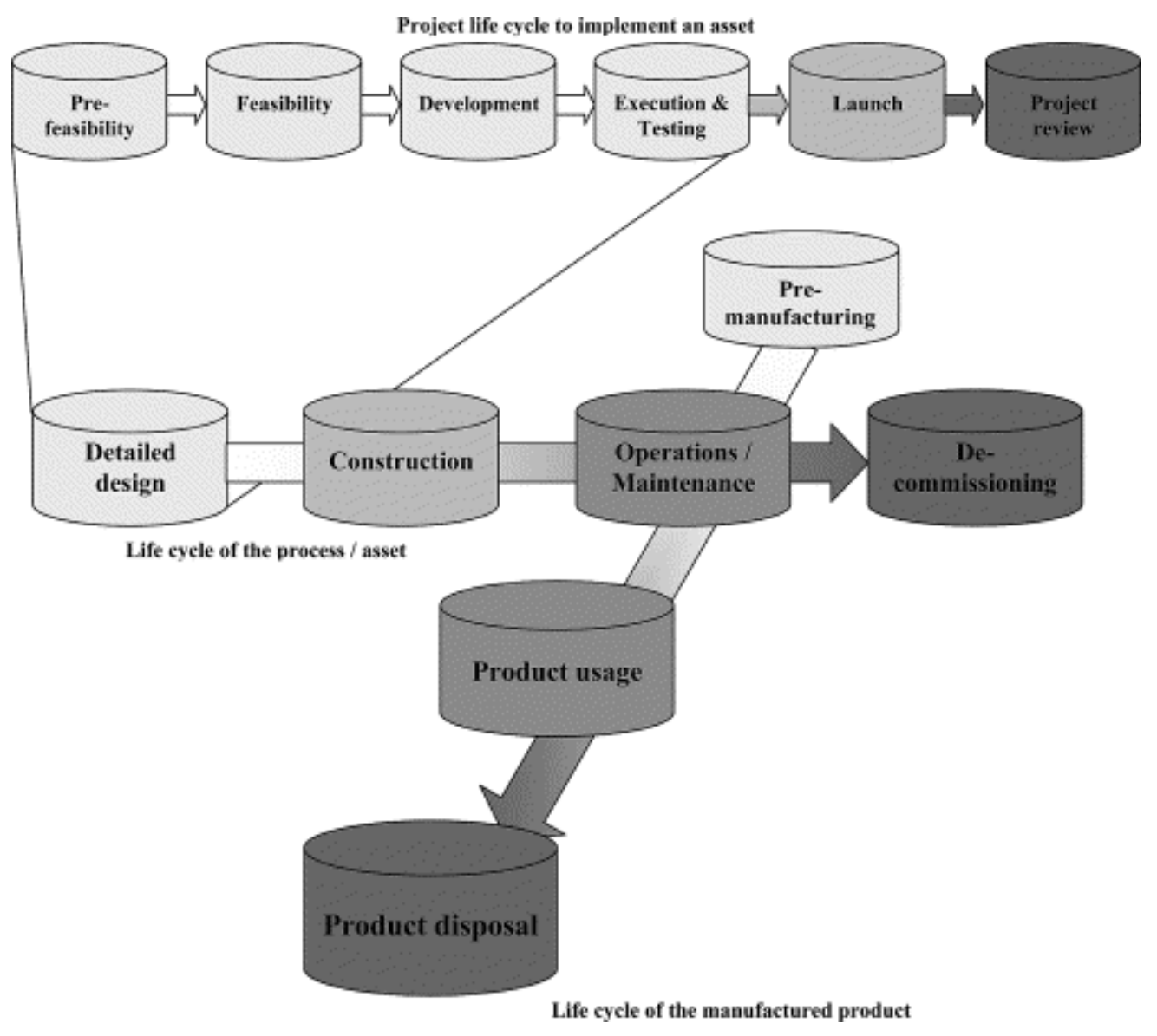

Fig. 1. Integration of typical project, asset and product life cycles in manufacturing industries [11]

\subsection{Product life cycle management and supply chain management}

The life cycle of a product consists of a chain of processes that includes raw material extraction, production, transportation, use, and disposal of the product (Fig. 2) [12]. Each unit process utilises various inputs (natural resources and energy) and outputs (emissions and releases to air, water, and land). Only by summing the burdens (and benefits) of all upstream and downstream processes for products, can they truly be evaluated comprehensively from a manufacturer's perspective [12]. 


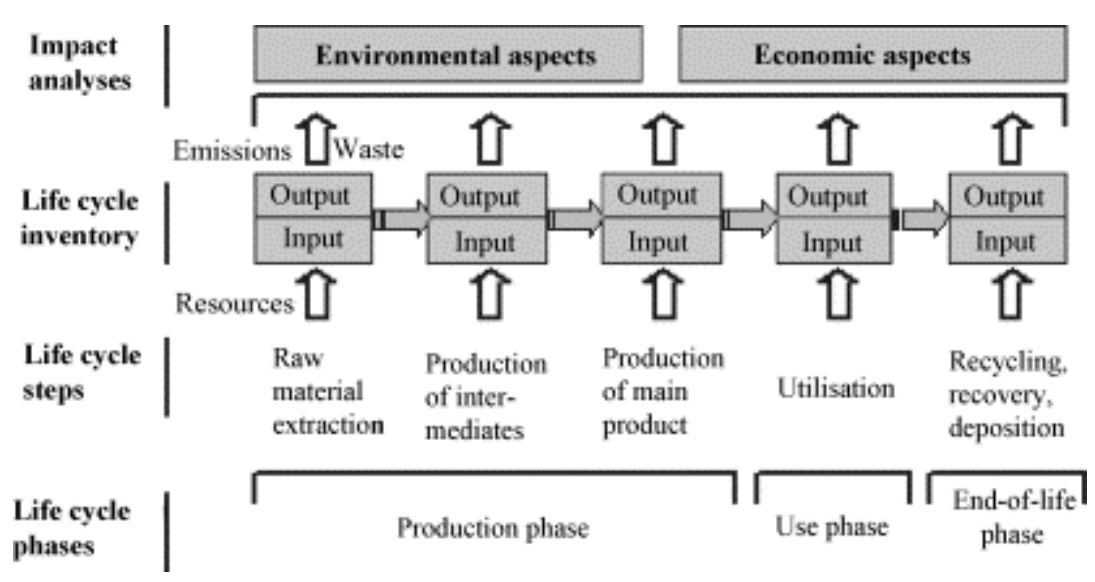

Fig. 2. The life cycle approach for "cradle-to-grave" assessments of products [12]

Sustainable product LCM, or product stewardship [9], implies the incorporation of the principles of supply chain management, whereby the manufacturer of a product assumes responsibility for the economic, environmental and societal consequences of supplied components, materials and energy inputs. However, little attention is given to the actual societal influences of suppliers [13]. Rather, the current focus is to increase the environmental performance of the supply chain [13 and 14], which originates from the integration of supply chain management and environmental pressures [15]:

- It is recognised that systematic approaches to environmental concerns in buyer-supplier systems are necessary.

- Buyer-supplier relations play an increasingly important role in industrial systems and the strategies of companies.

- External environmental pressures have implications on the internal behaviour of companies in supply chain systems.

Although large manufacturing facilities or customers are exerting pressure on the suppliers, the responses from within the supply chain vary. Supplying companies are often hesitant to invest in environmental innovations, as there is no clear correlation with financial performances. Especially smaller, lower profile suppliers, integral parts of any manufacturing system, lack incentives to improve environmental performance, whereas larger, higher profile suppliers respond positively to considerable pressures from customers [16].

The environmental pressures that are exerted by larger manufacturing facilities are often the result of the performance requirements of these facilities in terms of Environmental Management Systems that have been introduced, e.g. ISO 14000. Purchasing is one of the key processes assessed by ISO 14000 and the procurement process is progressively more recognised to significantly affect the corporate performance along environmental dimensions [17]:

- Directly, i.e. products acquired from the supply chain increase waste during the storage, transportation, processing, use or disposal of these purchased items, and 
- Indirectly, i.e. procured items do not consist of a direct monetary cost solely, but also of an environmental burden associated with producing or manufacturing these items.

For a complex product, e.g. the automobile, the total burden associated with the product is therefore dependent on accumulated internal and external burdens (Fig. 3). These burdens can translate to a total cost (purchasing and manufacturing burdens) of the final product or a total environmental impact associated with the product. Improvement approaches for supply chain management have been based on an assessment of environmental performance, and the addition of value, of the supplied item to the final product [18 and 19]. Where a potential for improvement in the supply chain is identified, smaller companies are often assisted through the introduction of technology and operational strategies [20].

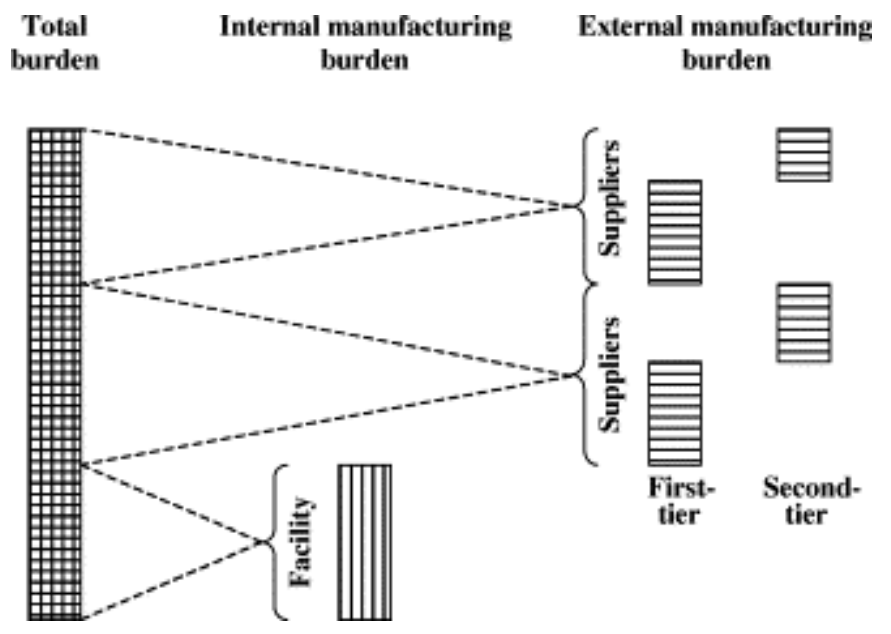

Fig. 3. Accumulated burdens (economic and environmental) of a manufactured product.

The lack of environmental data to determine the precise environmental impacts of supplying companies in industry is common in South Africa [2]. In particular, smaller supplying companies in the manufacturing value chain of the South African automotive sector have only limited process information. Automobile original equipment manufacturers (OEMs) in South Africa have commenced to systematically obtain the limited information and specifically: water usage, energy usage, and waste produced per manufactured item [20]. These three process parameters do not directly show the overall burden of a supplying company on the environmental resources of South Africa. This paper aims to introduce an environmental performance resource impact indicator (EPRII) procedure for OEMs, whereby the environmental performance of South African suppliers can be evaluated and compared (in terms of overall economic expenditure characteristics of OEMs), and improvement possibilities identified. 


\section{Environmental performance resource impact indicator (EPRII) procedure}

\subsection{Resource impact indicator (RII) calculation procedure}

A life cycle impact assessment (LCIA) framework has been introduced, which assesses the impacts associated with a system on four environmental resource groups as areas of protection (AoP): water, air, land, and mined abiotic resources [21]. Protection of the resource groups (except mined abiotic resources) ensures that the ambient environment is adequate to sustain human health and ecosystem quality without adverse effects. Based on a distance-to-target approach, the current and target ambient state levels define the importance of conventional LCIA midpoint categories that contribute to the total impact of a system on the resource groups. The current and target state levels are defined for four South African life cycle assessment (SALCA) regions (in Table 1), and for South Africa as a whole. The SALCA regions are shown in Fig. 4. The precautionary principle is followed to determine a maximum RII for a system for each resource group [21]. Thereby, the impact pathway of a life cycle inventory (LCI) constituent of a system that contributes to a RII value for any of the resource groups is taken into account. Furthermore, the summation of all the LCI contributions for a resource group is assigned as the RII for that resource group. The RII values for a life cycle system are calculated according to the following general equation [21]:

$$
R U I \mathrm{G}=\sum_{\mathrm{C}} \sum_{\mathrm{X}} Q_{\mathrm{x}} \cdot \mathrm{C}_{\mathrm{e}} \cdot \mathrm{N}_{\mathrm{e}} \cdot \mathrm{S}_{\mathrm{C}}
$$

where $\mathrm{RII}_{\mathrm{G}}$ is the RII impact indicator calculated for a main resource group through the summation of all impact pathways of LCI constituents, $Q_{X}$ is the quantity release to or abstraction from a resource of life cycle constituent $\mathrm{X}$ of an LCI system in an impact category $C$. The measurement units are specific to the LCI constituents. $C_{C}$ is the characterisation factor for an impact category (of constituent X) within the pathway [21 and 22]. Characterisation factors are typically measured as equivalence units, and Table 1 summarises the measurement units for the classified midpoint impact categories. For example, a release of methane into the atmosphere by a system contributes to the impact category global warming potential. The category is measured in units of $\mathrm{kg} \mathrm{CO}_{2}$ equivalence, and $1 \mathrm{~kg}$ of released methane is assigned a value of $21 \mathrm{~kg} \mathrm{CO}_{2}$ equivalence. Characterisation factors for the four resource groups have been compiled for a large number of possible inventory constituents [23]. $N_{\mathrm{C}}$ is the normalisation factor for the impact category based on the ambient environmental quantity and quality objectives, i.e. the inverse of the target state of the impact category. The units are those summarised in Table 1 . And $S_{\mathrm{C}}=C_{\mathrm{S}} / T_{\mathrm{S}}$ is the significance (or relative importance) of the impact category in a resource group based on the distance-to-target method, i.e. current ambient state $\left(C_{\mathrm{S}}\right)$ divided by the target ambient state $\left(T_{\mathrm{S}}\right)$. Table 1 summarises these current and target ambient state values for the SALCA regions of South Africa.

Table 1. Current and target values for the classified categories and SALCA regions [21] 


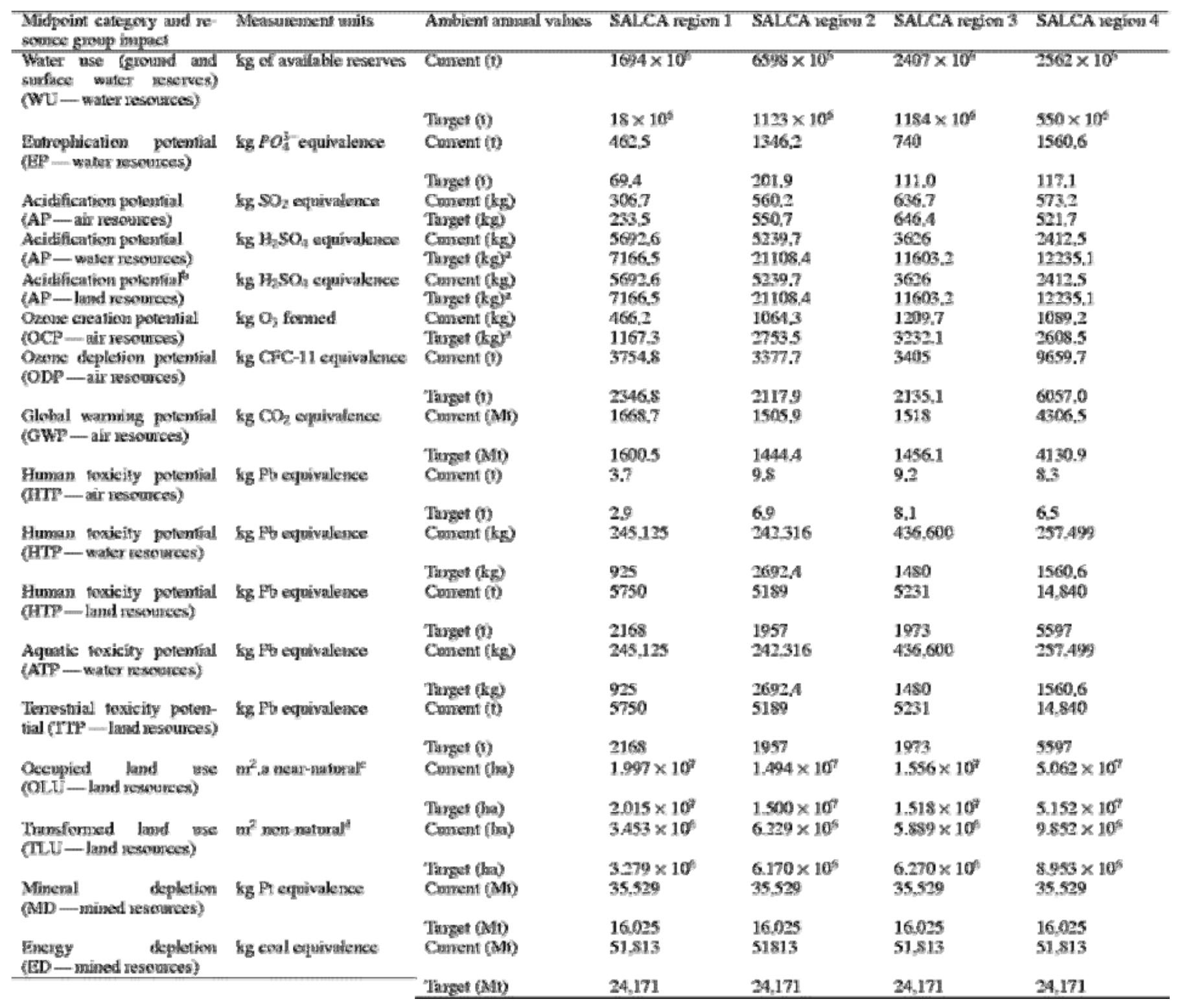




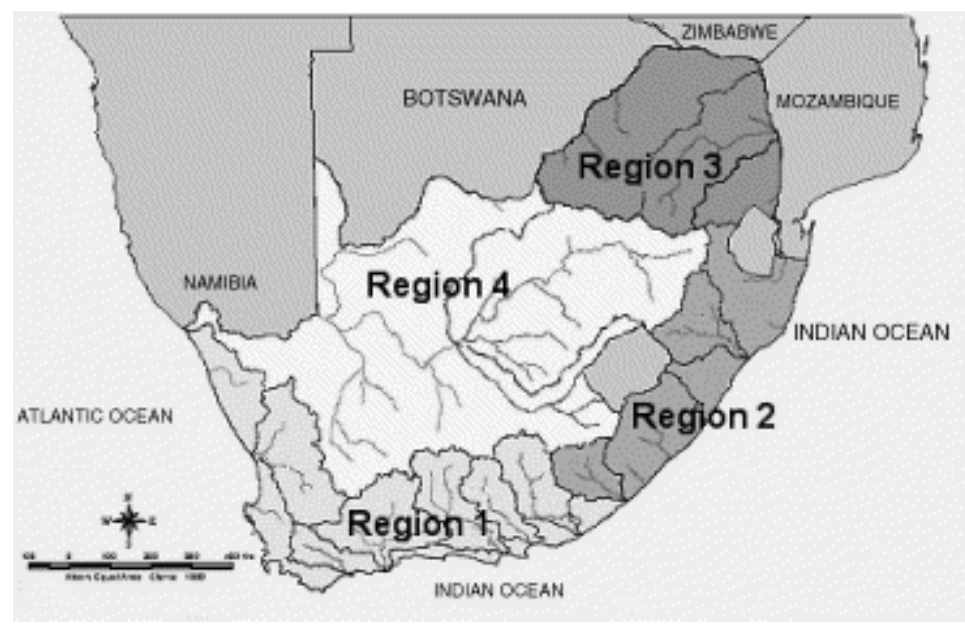

Fig. 4. SALCA regions for South Africa to define current and target ambient environmental state values [21]

Fig. 5 illustrates the possible impact pathways of the three process parameters that are obtained from suppliers to automotive OEMs in South Africa. Through the framework of Fig. 5 and the calculation procedure of Eq. (1) an overall burden indicator of a company (or manufacturing process) can be determined on the four resource groups. In order to apply the framework and RII calculation procedure, detailed LCIs were compiled for energy usage, i.e. electricity, steam and liquid fuel, and waste produced in South Africa [24]. For the latter it was assumed that a South African medium sized landfill for lowlevel hazardous material would be required as an average. Water usage is assumed as direct extraction from surface or groundwater reserves. Similarly, the use of raw energy materials, e.g. natural gas and coal are taken as directly extracted from available reserves. 


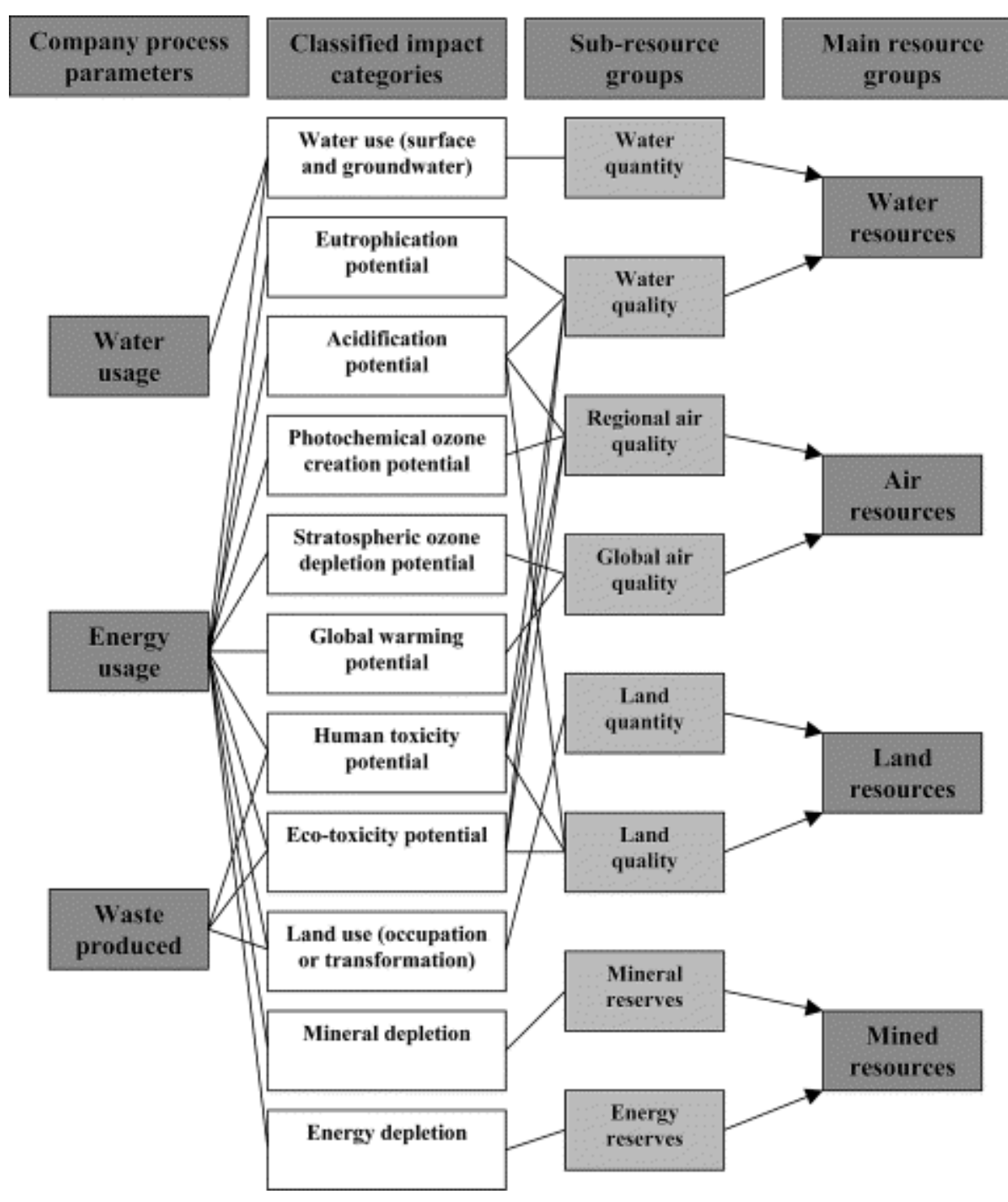

Fig. 5. Framework to calculate the RII values of obtainable process parameters of companies in the South African automotive supply chain.

The use of liquid fuel and raw energy materials is not region-specific and South African normalisation values are used. The majority of electricity in South Africa is generated in SALCA Region 3 [25], and the RII values per MJ used are calculated with the normalisation values for this region. RIIs for the other process parameters are calculated using the normalisation values for the SALCA Regions where a company is located. As an example, Table 2 shows RII values that have been calculated for selected process parameters, using South Africa as a single region.

Table 2. RII values for selected process parameter (with South Africa as one region) 


\begin{tabular}{|c|c|c|c|c|}
\hline Progess parameter ${ }^{2}$ & Waker peseources & Air resempess & Land werevureses & Mined abiotien resenuecs. \\
\hline Whste prodnced $-1 \mathrm{~kg}$ & $4.719 \times 10^{-8}$ & $1.506 \times 10^{-1 / 2}$ & $2750 \times 10^{-4}$ & 0 \\
\hline Elestrisity used $-1 \mathrm{MU}$ & $4.533 \times 10^{-3}$ & $1026 \times 10^{-4}$ & $9.650 \times 10^{-7}$ & $5.097 \times 10^{-7}$ \\
\hline Liquid fuel used $-1 \mathrm{~kg}$ & $8.756 \times 10^{-3}$ & $1.104 \times 10^{-4}$ & $1.043 \times 10^{-6}$ & $1.653 \times 10^{-5}$ \\
\hline Xatoral gas used-1 kg & 0 & 0 & 9 & $4.955 \times 10^{-5}$ \\
\hline Ceal used $=1 \mathrm{~kg}$ & 0 & 0 & 0 & $3.599 \times 10^{-5}$ \\
\hline Steam used $-1 \mathrm{~kg}$ & $7.324 \times 10^{-5}$ & $7.061 \times 10^{-7}$ & $1.242 \times 10^{-5}$ & $4.283 \times 10^{-7}$ \\
\hline Water ned-1 kg & $4.856 \times 10^{-8}$ & 0 & 0 & 0 \\
\hline
\end{tabular}

${ }^{\mathrm{a}}$ The correlations between the process parameters and related RII values are linear.

${ }^{\mathrm{b}}$ The calculated RIIs are dimensionless.

\subsection{Environmental performance resource impact indicator procedure}

An environmental performance indicator (EPI) approach has further been introduced [21] to compare the performance of one set of obtained process parameters (energy and water usage, and waste produced) to another in terms of calculated RIIs. The approach applies a simple ranking value procedure that assigns a qualitative impact value of 1,0 , and -1 to the resource groups, based on the RII performance of one manufacturing system (or set of obtained process parameters) compared to another. Subjective weighting values for the resource groups are used to calculate an overall single score or EPRII for the evaluated companies. The subjective values are based on the perceptions of managers and directors in the manufacturing sector of South Africa, and the distribution of the annual national government budget expenditure on environmental issues [21 and 26]:

- Water resources- 0.475 ;

- Air resources-0.120;

- Land resources-0.200;

- Mined abiotic resources- -20.205 .

\section{Performance evaluation of three automotive OEM suppliers in South Africa}

The environmental performances of three first-tier suppliers to an automotive OEM in South Africa have been evaluated and compared using the EPRII methodology. The companies supply the OEM with fuel tanks, windscreens and tyres for a standard sedan vehicle. Table 3 provides an estimate of the process parameters that have been obtained for the companies per supplied component. The table also provides an estimate of the economic cost of the supplied components to the OEM.

Table 3. Process parameters obtained from an OEM's first-tier suppliers 


\begin{tabular}{|c|c|c|c|}
\hline & Fuel tank & Windscreent & Tyer \\
\hline Enatyy nerge & & & \\
\hline Elecwieify (AT) & 63.7 & 60.5 & 234.1 \\
\hline Liquid ficl (diesel) (kg) & 00 & 0 & 0 \\
\hline Steam $(\mathrm{kg})$ & 00 & 0 & 39.4 \\
\hline Raw energy naterials (kg) & 00 & $2 \theta^{\prime}$ & 0 \\
\hline Watcr urage $(\mathrm{kg})$ & 46 & 1768 & 20.5 \\
\hline Waste produced (kg) & 0.1 & 320 & $10 \%$ \\
\hline Ecomomie value $(\mathrm{R})$ & 100000 & 146000 & 500.00 \\
\hline
\end{tabular}

All of the first-tier suppliers are located in SALCA Region 3 in close vicinity of the OEM's manufacturing facility. The associated RII values for the each company per supplied component are summarised in Table 4. In order to compare the environmental performances of the first-tier suppliers equally from an OEM assembly facility's perspective, the RII values are further normalised with the economic cost of the components, i.e. the RII values are given per South African Rand (ZAR). Fig. 6 compares these normalised RII values for the three components.

Table 4. RII values calculated for the three manufactured components

\begin{tabular}{llll}
\hline \hline & Fuel tank & Windsercen & Tyre \\
\hline Wafer resouves & $2.852 \times 10^{-1}$ & $2779 \times 10^{-1}$ & $1.067 \times 10^{2}$ \\
Air nesorves & $6.535 \times 10^{-1}$ & $6.206 \times 10^{-3}$ & $2.406 \times 10^{-2}$ \\
Lamd rescuices & $6.148 \times 10^{-5}$ & $6.113 \times 10^{-5}$ & $2.271 \times 10^{-4}$ \\
Mined abiotic reseurces: & $3.222 \times 10^{-5}$ & $4.051 \times 10^{-5}$ & $1.271 \times 10^{-4}$ \\
\hline
\end{tabular}

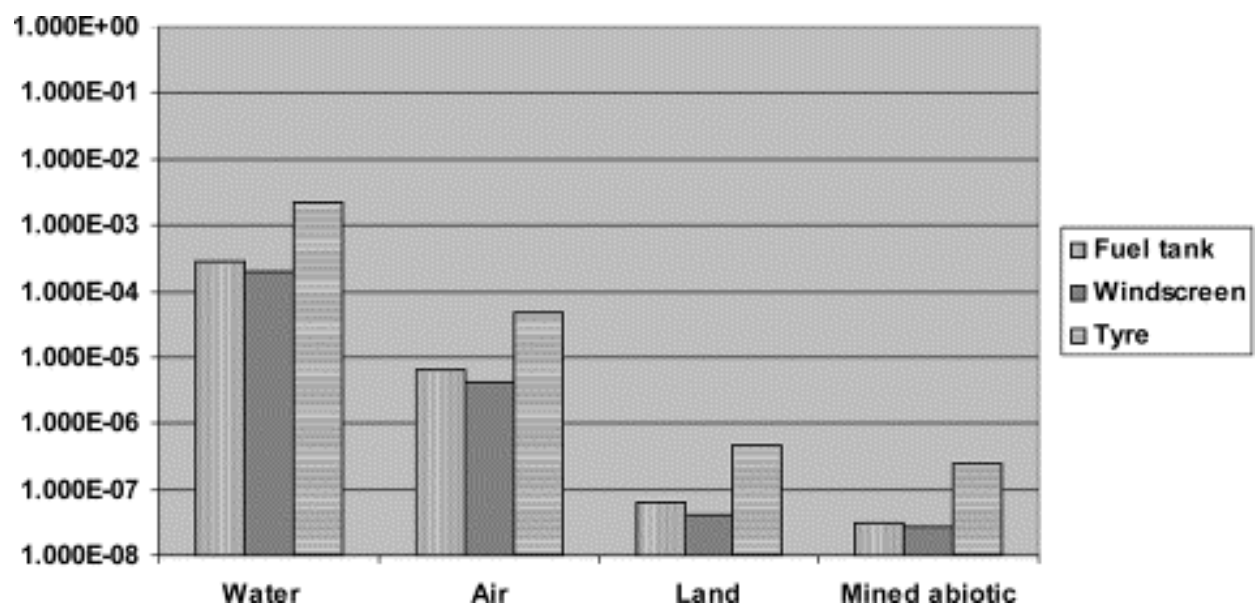

Fig. 6. RII values for the three supplied components per South African Rand.

Table 4 indicates that electricity usage is the most important process parameter if the RII calculation procedure is applied to evaluate the environmental performances of the firsttier suppliers. It must be noted that the impacts associated with this parameter are not region-specific in South Africa. Electricity usage has an impact on most of the classified impact categories (of Fig. 5) and all of the resource groups (see Table 2), as has been reported [27, 28 and 29]. However, the burdens on water resources $\left(\mathrm{RII}_{\mathrm{W}}\right)$ are calculated to be the highest in South Africa. The impacts on the water resources are primarily 
attributable to the acidification potential, human toxicity potential, and aquatic toxicity potential categories. The ambient environmental state in SALCA Region 3, which is used for (distance-to-target) normalisation purposes, therefore signifies these categories to be the most important for the electricity LCI.

The EPRII procedure prioritises the suppliers of tyres (per economic cost) to receive attention in terms of improving environmental performances, followed by the fuel tank. The ranking procedure and subjective weighting values of the four resource groups do not influence the outcome of the environmental performances evaluation and comparison (for these first-tier suppliers). This is due to large contribution of electricity usage to the calculated (total) RIIs for all three of the first-tier suppliers. If different process parameters (between compared suppliers) are important in terms of influencing calculated RIIs, the same trends in the compared RII values will not be observed and the ranking procedure and subjective weighting values would consequently be required for an overall comparison of the suppliers. For example, the manufacturers of certain metallic components often use high quantities of liquid fuel, which also has a high impact on all of the resource groups (see Table 2).

\section{Conclusions}

This paper introduces a South African region-specific environmental evaluation procedure, whereby additional stresses of an operation's supply system are determined based upon current water, air, land, and mined resources for four SALCA regions. The influence of region specificity on the calculated RIIs from the evaluation procedure of life cycle systems has been demonstrated [21]. However, when assessing environmental performances in the South African automotive supply chain, it is not expected that a regional focus within the country would influence the results much. Therefore, it is proposed to base the evaluation on the country as a single region. RII values for selected process parameters in the South African context have subsequently been provided (see Table 2).

The paper incorporates the economic cost of the supplied components into the evaluation process. Normalising the environmental burdens of supplier activities with the economic cost of the supplied components provides a means to equally compare the burdens at an operational level, i.e. environmental performances (of the supply chain) can be linked to expenditure trends (of an OEM assembly facility). However, this is not an indication of the total environmental burdens associated with the final product (Fig. 2). This is exemplified in the automobile-manufacturing industry, which was used as an example to apply the EPRII approach to supply chain management:

- The supplied tyre has the highest overall environmental burden per Rand spent (in the order of a factor of 10 compared to the fuel tank and windscreen). However, a supplied tyre has an economic value of half to a third compared with the fuel tank and windscreen, and the ratio difference between environmental burdens associated with the complete components would therefore be smaller. Conversely, for the specific studied sedan, five 
tyres are supplied per manufactured automobile, which would increase the environmental burdens (and total cost to the supplier) by a factor of five.

- The manufacturing activities of the first-tier suppliers were considered only, as is the current case in the South African automobile-manufacturing sector. Second and subsequent tiers would have to be included to obtain an indication of the overall environmental burdens, although the economic cost of the components to the OEM would not change. This has proven to be difficult for tiers that are further away from the OEM, especially for smaller companies in South Africa and where secondary components are imported.

From the perspective of an automotive product system, the EPRII procedure should rather reflect the environmental burdens associated with the final assembled product. Thereby, OEMs would be provided with the means to obtain a first approximate of environmental concerns in the supply chain (per manufactured product) based on three basic process parameters: water and energy usage, and waste produced. Tiers can subsequently be prioritised to determine where assistance is required to improve environmental performances. Research has commenced to study the supply chain of one OEM in South Africa in greater detail, where the EPRII tool will be used.

The EPRII approach could similarly be applied in project and asset management, where detailed data are often limited to base substantial environmental evaluations on. In South Africa, this is especially true during the design stages of technologies in the processmanufacturing industry [11].

\section{References}

1. Sampson I. Introduction to a legal framework to pollution management in South Africa. Deloitte \& Touche and South African Water Research Commission report, no. TT 149/01, Pretoria, South Africa, 2001.

2. A.C. Brent, M.B. Rohwer, E. Friedrich and H. von Blottnitz, Overview: LCA in South Africa: status of life cycle assessment and engineering research in South Africa. Int J Life Cycle Assess 73 (2002), pp. 167-172.

3. Labuschagne C, Brent AC. Sustainable project life cycle management: the need to integrate life cycles in the manufacturing sector. Int J Project Management 2003; in review.

4. R. Buttrick, The project workout: a toolkit for reaping the rewards from all your business projects. , Prentice Hall, London (2000).

5. Schuman C, Brent AC. Asset life cycle management: towards improving asset performance. Int J Oper Prod Management 2003; in review. 
6. B.S. Blanchard, Logistics engineering and management. (5th ed.), Prentice Hall, Upper Saddle River, NJ (1998).

7. B.S. Blanchard and W.J. Fabrycky, Systems engineering and analysis. (3rd ed.), Prentice Hall, Upper Saddle River, NJ (1998).

8. New South Wales Asset Management Committee. Total Asset Management: Sustainable Development Guideline. Department of Public Works and Services Report number 01050, Sydney, Australia; 2001.

9. US Environmental Protection Agency (EPA). Product Stewardship. http://0www.epa.gov.innopac.up.ac.za:80/epaoswer/non-hw/reduce/epr/, accessed on 26 November 2003.

10. International Organisation for Standardisation (ISO). Systems engineering: system life cycle processes. ISO/IEC 15288:2002 standard, http://www.iso.org, accessed on 26 November 2003.

11. C. Labuschagne. Sustainable project life cycle management: criteria for the South African process industry, Department of Industrial and Systems Engineering, University of Pretoria, Pretoria, South Africa (2003).

12. J. Sevitz, A.C. Brent and A.B. Fourie, An environmental comparison of plastic and paper consumer carrier bags in South Africa: implications for the local manufacturing industry. South African J Ind Eng 141 (2003), pp. 67-82.

13. BMW Group. Sustainable Value Report 2003/2004.

http://www.bmwgroup.com/sustainability, accessed on 26 November 2003.

14. Engineering News. Car maker's suppliers to be ISO 14001 accredited by 2005 . http://www.engineeringnews.co.za/eng/sector/automotive/, accessed on 26 November 2003.

15. J. Hall, Environmental supply chain dynamics. J Cleaner Prod 8 (2000), pp. 455471.

16. R. Handfield, S.V. Walton, R. Stroufe and S.A. Melnyk, Applying environmental criteria to supplier assessment: a study in the application of the analytical hierarchy process. Eur J Oper Res 141 (2002), pp. 70-87.

17. B. Beamon, Designing the green supply chain. Logistics Inform Management 124 (1999), pp. 332-342.

18. K. McIntyre, H. Smith, A. Henham and J. Pretlove, Environmental performance indicators for integrated supply chains: the case of Xerox Ltd. Supply Chain Manage 33 (1999), pp. 149-156. 
19. R.I. van Hoek, Case studies of greening the automotive supply chain through technology and operations. Int J Environ Technol Management 12 (2001), pp. 140-163.

20. Brent AC. Personal communications with automobile Original Equipment Manufacturers (OEMs), 2002.

21. Brent AC. A life cycle impact assessment procedure with resource groups as areas of protection. Int J Life Cycle Assess 2003; in press.

22. J.B. Guinée, M. Gorrée, R. Heijungs, G. Huppes, R. Kleijn, A. de Koning et al.. Life cycle assessment - an operational guide to the ISO standards, Centre for Environmental Studies (CML), Leiden University, Leiden, The Netherlands (2001).

23. Brent AC. Environmental Performance Resource Impact Indicator. Department of Engineering and Technology Management, University of Pretoria, Pretoria, South Africa, 2003; http://www.up.ac.za/academic/etm/engmot/lce/impact.htm, accessed on 26 November 2003.

24. Brent AC. Life Cycle Engineering Inventories. Department of Engineering and Technology Management, University of Pretoria, Pretoria, South Africa, 2003; http://www.up.ac.za/academic/etm/engmot/lce/inventory.htm, accessed on 26 November 2003.

25. Eskom. Environmental Information 2002. Company environmental report 2001; http://www.eskom.co.za/Enviro\%20data\%202002/report01/index.htm, accessed on 26 November 2003.

26. Brent AC, Heuberger R, Manzini D. Evaluating projects that are potentially eligible for Clean Development Mechanism (CDM) funding in the South African context: establishing weighting values for sustainable development criteria. Environ Develop Econom 2003; in review.

27. Y. Matsuno and M. Betz, Development of life cycle inventories for electricity grid mixes in Japan. Int J Life Cycle Assess 55 (2000), pp. 295-305.

28. J. May and D. Brennan, Application of data quality assessment methods to an LCA of electricity generation. Int J Life Cycle Assess 84 (2003), pp. 214-225.

29. L. Coltro, E. Garcia and G. Queiroz, Life cycle inventory for electric energy system in Brazil. Int J Life Cycle Assess 85 (2003), pp. 290-296.

Corresponding author. Tel.: +27-12-420-3929; fax: +27-12-362-5307. 